\title{
A Calculation Model of the Net Pressure for Forming Map Cracking in Coalbed with Cleats During Hydraulic Fracturing Process
}

\author{
Li Yuwei*, Ai Chi and Liu Yazhen
}

\author{
Key Laboratory of Education Ministry for Enhanced Oil Recovery, Northeast Petroleum University, Daqing, \\ Heilongjiang, China
}

\begin{abstract}
An important prerequisite for achieving efficient exploitation of coalbed methane wells is through forming map cracking by hydraulic fracturing. In order to analyze the mechanical mechanism for forming map cracking of the coal bed with cleats, the mechanical conditions for forming map cracking during hydraulic fracturing process of coal bed were proposed using extensional faulting in elastic mechanics and the shear damage criterion, and the minimum net pressure calculation model for forming map cracking was established when the butt cleat and face cleat in coal opened at the same time. It can be concluded through using the calculation model that the net pressure value that needed for forming map cracking first decreased and then increased with the increasing of the angle between the face cleat and the direction of horizontal minimum principal stress. The cleats and fissures developed along the horizontal maximum principal stress were easy to open and extend under the effect of hydraulic fracturing. The variation of the internal friction coefficient variation of the face cleat had little effect on the minimum net pressure that was needed for forming map fracturing after the angle between the direction of face cleat and horizontal minimum principal stress is determined.
\end{abstract}

Keywords: Coal bed, hydraulic fracturing, map cracking, net pressure.

\section{INTRODUCTION}

Hydraulic fracturing is the important technical method to improve the productivity of coalbed methane wells and realize the efficient exploitation of coalbed methane [1-5]. Network fracturing techniques are a new kind of hydraulic fracturing technology which has been widely used in recent years. It could make the nature fractures or weak cemented plane open, or develop new branched fractures in the coal body, eventually form the crisscrossed network system which regards the main fracture as the trunk [6]. Dingwei Weng [7] analyzed the forming conditions of map cracking in reservoirs that natural fractures well-developed and got that it could form map cracking when net pressure exceeded the difference of horizontal principal stresses. Haifeng Zhao and Mian Chen [8] studied the forming mechanism of map cracking and activation mechanism of closed natural fractures based on the theory of fracture dynamics of rock. Shama [9] got the influence of the angle of main fractures and natural fractures and the difference of horizontal stresses relationship on map cracking forming conditions during hydraulic fracturing process in hard fractured reservoir through studies based on fluid-solid coupling theory. Former studies on the mechanics problems of map cracking during hydraulic fracturing process in coal bed with cross-developed face cleats and butt cleats are still rare. This paper established the minimum net pressure calculation model for the forming conditions of map cracking when face cleats and butt cleats

*Address correspondence to this author at the College of Petroleum Engineering, Northeast Petroleum University, Daqing 163318, Heilongjiang province, China; Tel: 0086-459-6503073;

E-mail: liyuweibox@126.com open at the same time using the theory of elastic mechanics, and provide the construction design basis for coalbed with cleats hydraulic fracturing.

\section{PHYSICAL MODEL OF THE PROPAGATION OF HYDRAULIC FRACTURES IN COALBED WITH CLEATS}

Coal rock is a kind of fractured rock mass in which lots of cleats, fractures and weak planes develop. Among those face cleats and butt cleats deliver on the space into a three dimensional mesh. Face cleats have good continuity, while the butt cleats develop only between two face cleats, and approximately vertical to level with poor general continuity [10] (as shown in Fig. 1). Owing to the large amounts of cleats and fractures, the fractures propagation mechanism during hydraulic fracturing are largely different to the fractures propagation in conventional sandstone reservoir, mainly showing that the communication between the hydraulic fractures and cleats can make map cracking open and propagate.

The physical model of the propagation of hydraulic fractures in coalbed with cleats is established (as shown in Fig. 2) in order to analyze the forming mechanism of map cracking through coal seam hydraulic fracturing fracture propagate and communicate cleats and weak planes. Coal rock body is under the effect of horizontal maximum principal stress $\sigma_{\mathrm{H}}$ and horizontal minimum principal stress $\sigma_{\mathrm{h}}$ when it is under the action of ground stress. Under this circumstance, face cleats and butt cleats cross-combined, angle between face cleats and minimum principal stress is $\theta$. Due to the approximately vertical cleat development of face cleats and butt cleats, we take the face cleats and butt cleats 


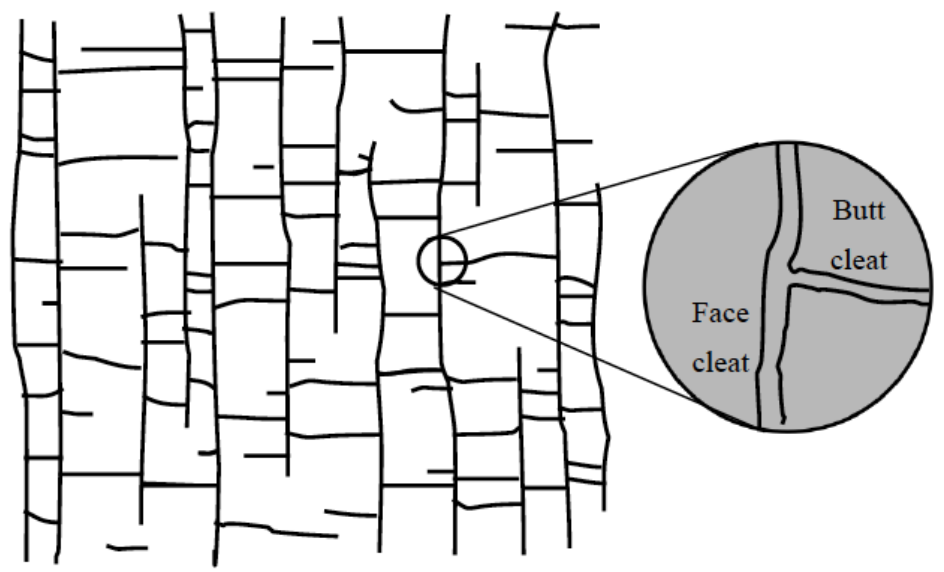

Fig. (1). The distribution of the system of coal bed cleats.

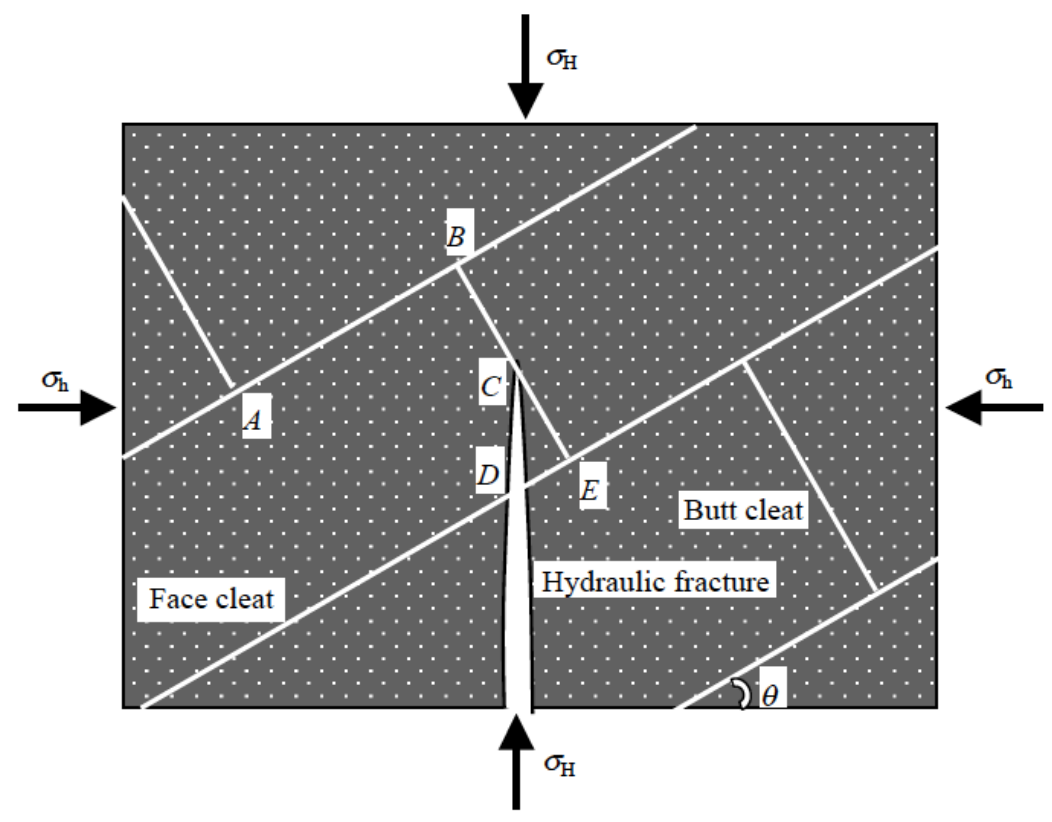

Fig. (2). The diagram of the hydraulic fracturing cracking extending schematic of the coal.

vertically distributed. Basic assumptions are put forward as follows: i) coal rock body is isotropic linear elastomer, and interaction of face cleats and end cleats can be ignored; ii) the net pressure in face cleats and butt cleats is unchangeable when they begin to initiate and propagate under the action of the fluid pressure in fractures; iii) the situation that coal rock body generate new branch fractures to form map cracking is not taken into consideration.

\section{THE CALCULATION MODEL OF NET PRESSURE OF FORM MAP CRACKING DURING HYDRAULIC FRACTURING PROCESS}

\subsection{The Forming Conditions of Map Cracking}

Cleats are the key to form map cracking during hydraulic fracturing process. In the propagating process of hydraulic fracture, it communicates with face cleats or butt cleats, and the fluid net pressure in fracture exerts on face or butt plane, and this leads to the propagation of cleats resulted from extensional faulting or shear failure.
For the propagation physical model of coalbed with cleats hydraulic fracturing established in this paper, the forming process and conditions of map cracking can be described as follows: The hydraulic fracture propagates along the direction of horizontal maximum principal stress communicates with face cleat $D E$ at point $D$, and under the effect of fluid pressure in the hydraulic fracture cleat $D E$ opens and propagates to butt cleat $B E$ and intersects at point $E$, if the fluid pressure can open butt cleat $B E$ and make it continue to propagate, the purpose of forming map cracking can be realized; If The hydraulic fracture propagates along the direction of horizontal maximum principal stress, communicates with face cleat $D E$ and it does not open, while hydraulic fracture continues to propagates to butt cleat $B E$ and intersects at point $C$, and under the effect of fluid pressure in the hydraulic fracture cleat $C B$ opens and propagates to face cleat $A B$, and makes it open and propagates. This can also realize the purpose of forming map cracking. So, to guarantee the forming of map cracking in coalbed with cleats during hydraulic fracturing, it is necessary that the fluid pressure in the hy- 
draulic fracture can make both face cleats and butt cleats open and propagate.

\subsection{The Calculation Model of Net Pressure during Form Map Cracking}

The wall pressure at point $D$ of fracture and face cleat $D E$ are the same when they are intersected, and it can be presented as follows:

$$
p_{\mathrm{f}}=p_{\text {net }}+\sigma_{\mathrm{h}}
$$

where: $P_{\mathrm{f}}$ is the wall pressure of fracture, $\mathrm{MPa} ; P_{\text {net }}$ is the fluid net pressure in fracture, $\mathrm{MPa} ; \sigma_{\mathrm{h}}$ is the horizontal minimum principal stress, $\mathrm{MPa}$.

According to the elastic mechanics stress analysis of fissures wall (Fig. 3), the normal stress and tangential stress acting on the fissures wall which dip is $\theta$ can be represented as:

$$
\left\{\begin{array}{l}
\sigma_{\mathrm{n}}=\sigma_{\mathrm{H}} \cos ^{2} \theta+\sigma_{\mathrm{h}} \sin ^{2} \theta \\
\tau_{\mathrm{s}}=\left(\sigma_{\mathrm{H}}-\sigma_{\mathrm{h}}\right) \sin \theta \cos \theta
\end{array}\right.
$$

where: $\sigma_{\mathrm{n}}$ is the normal stress, $\mathrm{MPa} ; \tau_{\mathrm{s}}$ is the tangential stress; $\sigma_{\mathrm{H}}$ is the horizontal maximum principal stress, MPa.

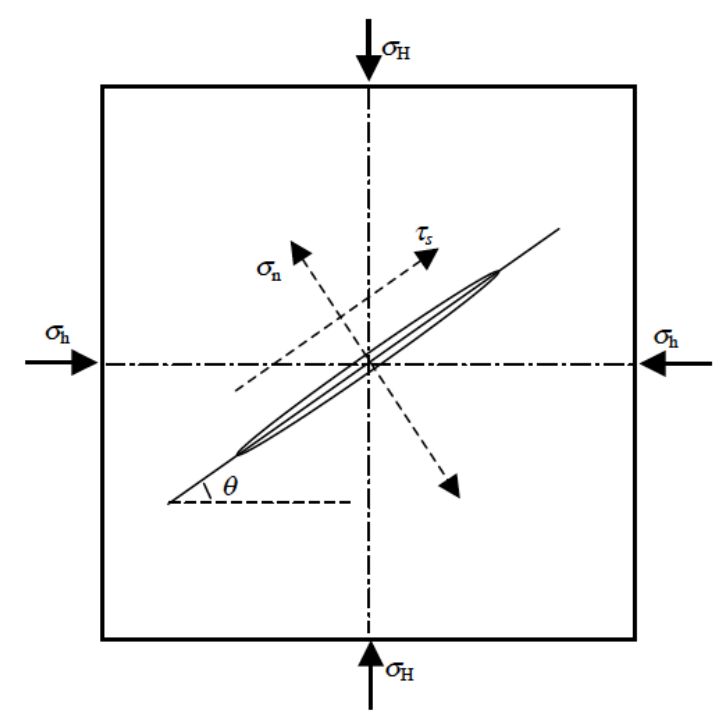

Fig. (3). The load schematic diagram of the surface of fissures.

Face cleat can generate two types of failure, extensional faulting or shear failure. Under the action of fluid pressure, the damage form depends entirely on the normal stress and shear stress exerted on face cleat wall. When tensile fracture occurs:

$$
p_{\mathrm{f}} \geq \sigma_{\mathrm{n}}
$$

If extensional faulting takes place at face cleat, the mechanical condition to generate shear slide is that:

$$
\tau_{\mathrm{s}} \geq \tau_{0}+\mu_{\mathrm{f}}\left(\sigma_{\mathrm{n}}-p_{\mathrm{f}}\right)
$$

where: $\tau_{0}$ is the adhesion of coal rock in face cleat, $\mathrm{MPa}$; $\mu_{\mathrm{f}}$ is the internal friction coefficient of face cleat wall.
According to type (1)-(4), the mechanical conditions that internal critical net pressure should meet respectively when extensional faulting or shear failure occurs to face cleat are:

$$
\begin{aligned}
& p_{\text {netm } z}=\left(\sigma_{\mathrm{H}}-\sigma_{\mathrm{h}}\right) \cos ^{2} \theta \\
& p_{\text {netm } \tau}=\left(\sigma_{\mathrm{H}}-\sigma_{\mathrm{h}}\right)\left(\cos ^{2} \theta-\frac{1}{i_{\mathrm{f}}} \sin \theta \cos \theta\right)+\frac{\tau_{0}}{i_{\mathrm{f}}}
\end{aligned}
$$

where: $P_{\text {netmz }}$ is the minimum net pressure when extensional faulting occurs to face cleat, $\mathrm{MPa} ; P_{\text {netm } \tau}$ is the minimum net pressure when shear failure occurs to face cleat, $\mathrm{MPa}$.

So, the minimum net pressure that ensures the face cleat to open is:

$$
p_{\text {netm }}=\min \left\{p_{\text {netm } z}, p_{\text {netm } \tau}\right\}
$$

where: $P_{\text {netm }}$ is the minimum net pressure in fracture when face cleat opens, MPa.

To the butt cleat in coal rock body, the deduction method of its determinant mechanical conditions for the butt cleat to open is the same as that of face cleat, so the mechanical conditions for butt cleat to generate extensional faulting or shear failure are:

$$
\begin{aligned}
& p_{\text {netd } z}=\left(\sigma_{\mathrm{H}}-\sigma_{\mathrm{h}}\right) \sin ^{2} \theta \\
& p_{\text {netd } \tau}=\left(\sigma_{\mathrm{H}}-\sigma_{\mathrm{h}}\right)\left(\sin ^{2} \theta-\frac{1}{i_{\mathrm{f}}} \sin \theta \cos \theta\right)+\frac{\tau_{0}}{i_{\mathrm{f}}}
\end{aligned}
$$

where: $P_{\text {netdz }}$ is the minimum net pressure when extensional faulting occurs to butt cleat, $\mathrm{MPa} ; P_{\text {netd } \tau}$ is the minimum net pressure when shear failure occurs to butt cleat, $\mathrm{MPa}$.

Also, the minimum net pressure that ensures the butt cleat to open is:

$$
p_{\text {netd }}=\min \left\{p_{\text {netd } z}, \quad p_{\text {netd } \tau}\right\}
$$

where: $P_{\text {netd }}$ is the minimum net pressure in fracture when butt cleat opens, MPa.

Finally, according to the forming conditions of map cracking in coalbed with cleats during hydraulic fracturing referred in section 3.1, to form map cracking the face cleat and butt cleat should both open, namely the net pressure in fracture should meet the mechanical condition that:

$$
p_{\text {net }}=\max \left\{p_{\text {netm }}, p_{\text {netd }}\right\}
$$

Type (11) is the mechanical condition of map cracking in coalbed with cleats during hydraulic fracturing process, this type also shows that when carrying out the coalbed hydraulic fracturing, the map cracking can be realized by controlling the value of net pressure in fracture.

\section{EXAMPLE CALCULATION AND ANALYSIS}

CBM Well HX-2 in the Hegang mining area, the horizontal maximum principal stress is $12.59 \mathrm{MPa}$, the horizontal minimum principal stress is $10.64 \mathrm{MPa}$, the angle between the face cleat and the horizontal minimum principal stress $\theta$ is $82.7^{\circ}$, the adhesion of coal rock in face cleat is 
$0.89 \mathrm{MPa}$, the adhesion of coal rock in butt cleat is 1.07 $\mathrm{MPa}$, the internal friction coefficient of face and butt cleat walls are 0.45 . By applying calculation model referred in this paper, it can be obtained that the minimum net pressure in fracture when face cleats open is $0.03 \mathrm{MPa}$, while the minimum net pressure in fracture when butt cleats open is $1.92 \mathrm{MPa}$, so the minimum net pressure that required to form map cracking is $1.92 \mathrm{MPa}$. When doing actual fracturing construction, influence of the existing friction was into consideration, so controlled net pressure in fracture was about 3.0 $\mathrm{MPa}$ during fracturing process. Through the deliverability analysis and evaluation after fracturing, it could be reckoned that this well formed map cracking proved the accuracy of the model.

\subsection{The Influence of The Angle Between The Face Cleat and The Direction of Minimum Principle Stress on The Minimum Forming Net Pressure for Map Cracking}

There is a little angle between the direction of face cleat propagation and horizontal minimum principle stress, this angle directly affects the normal stress and shear stress exerted on both face and butt cleat walls. The influence of angle $\theta$ is analyzed on the forming conditions of map cracking, and the angle $\theta$ ranges from 0 to $90^{\circ}$ (because $\theta$ changes periodically in $0-360^{\circ}$, and takes $0-90^{\circ}$ as a period) to calculate the minimum net pressure calculation required to form map cracking.

From the calculation results in Figs. 4-6 it can be obtained that the required minimum net pressure ensured face cleats to open continually decreases as the angle $\theta$ increases, the required minimum net pressure that ensures butt cleats to open continually increases as the angle $\theta$ increases, and the net pressure required to form map cracking first increases and then decreases. This shows that the face cleats become increasingly easy to open with the increasing of $\theta$, while it is opposite to butt cleats, it also shows that the cleats and fissures developed along the horizontal maximum stress are mostly easy to initiate and propagate under the action of water pressure. Besides, when $\theta$ was $0^{\circ}$ and $90^{\circ}$ the maximum net pressure to form map cracking is $1.95 \mathrm{MPa}$, equal to the difference of $\sigma_{\mathrm{H}}$ and $\sigma_{\mathrm{h}}$, this is also in accordance with the research conclusions made by most scholars.

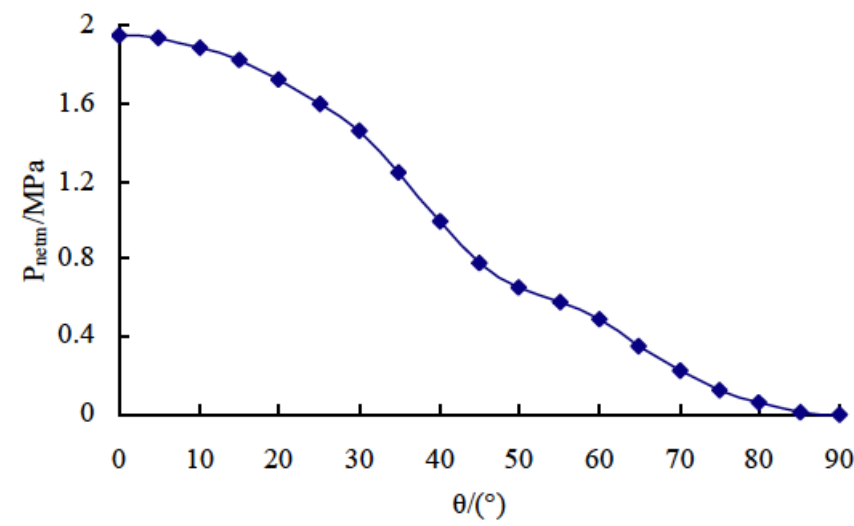

Fig. (4). The curve of cracking minimum net pressure for the opening of coal bed face cleat changing with the variation of angle $\theta$.

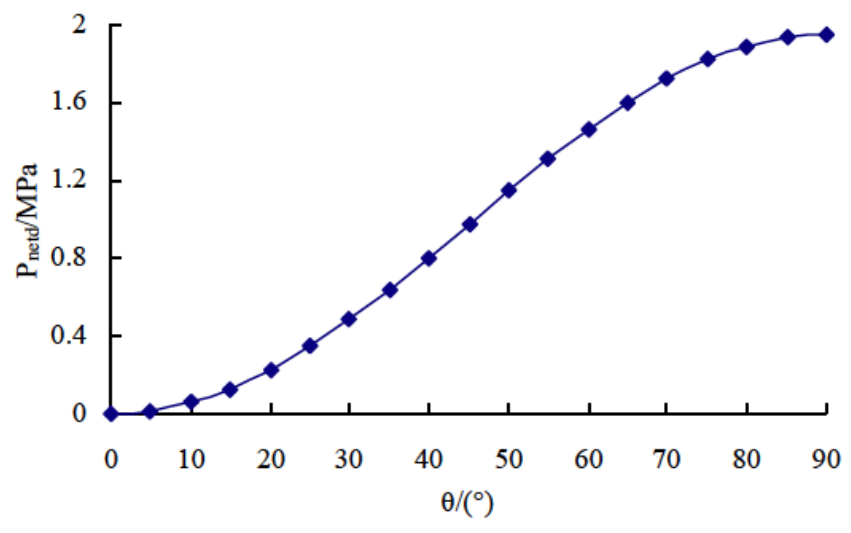

Fig. (5). The curve of cracking minimum net pressure for the opening of coal bed butt cleat changing with the variation of angle $\theta$.

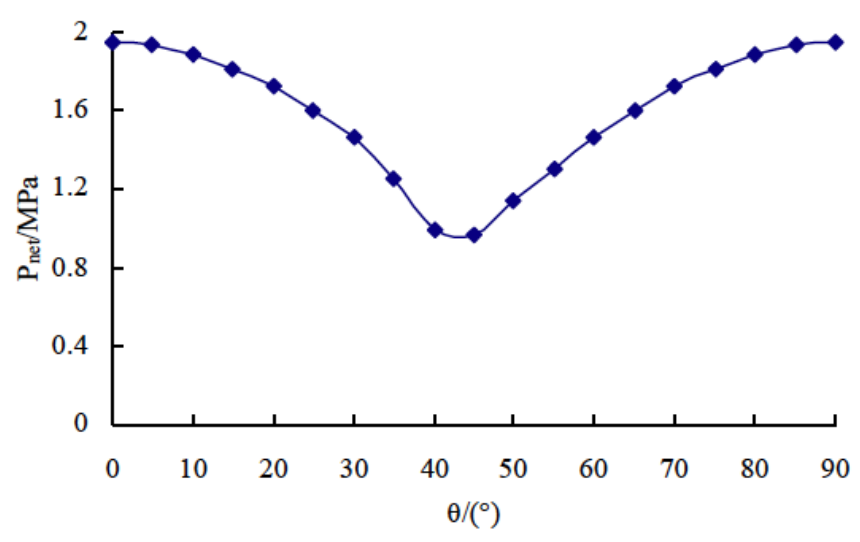

Fig. (6). The curve of minimum net pressure for forming map cracking of the coal bed under fracturing changing with the variation of angle $\theta$.

\subsection{The Influence of Internal Friction Coefficient of Wall on The Minimum Forming Net Pressure for Map Crack- ing}

The internal friction coefficient of the face cleat and the butt affect the bear the limit shear stress that the cleat could bear, which may affect the net pressure for map cracking initiation. In order to analyze the influence law, internal friction coefficient of wall is taken as $0.15-0.45$, and study its effects on the forming conditions of map cracking are studied.

From the calculation results in (Fig. 7, 8) it can be obtained that when the angle between the face cleat and the horizontal minimum principal stress $\theta$ is determined, the required minimum net pressure remains the same with the increase in internal friction coefficient of the face cleat wall, while when $\theta$ is around $40^{\circ}$ (the corresponding angle when the required net pressures are the same to both the face cleat and butt cleat), the required net pressure increases with the increase in internal friction coefficient, and the change is not obvious. This shows that once the angle between the face cleat and the horizontal minimum principal stress $\theta$ is determined, the change of internal friction coefficient of cleat wall has little influence on the required internal critical net pressure. 


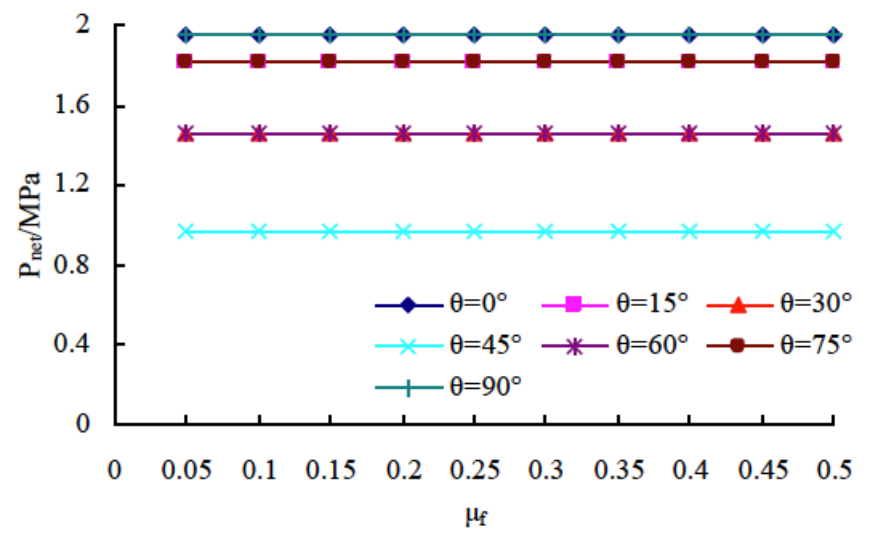

Fig. (7). The curve of minimum net pressure for forming map cracking changing with the variation of internal friction coefficient of the cleat face under different angle of $\theta$.

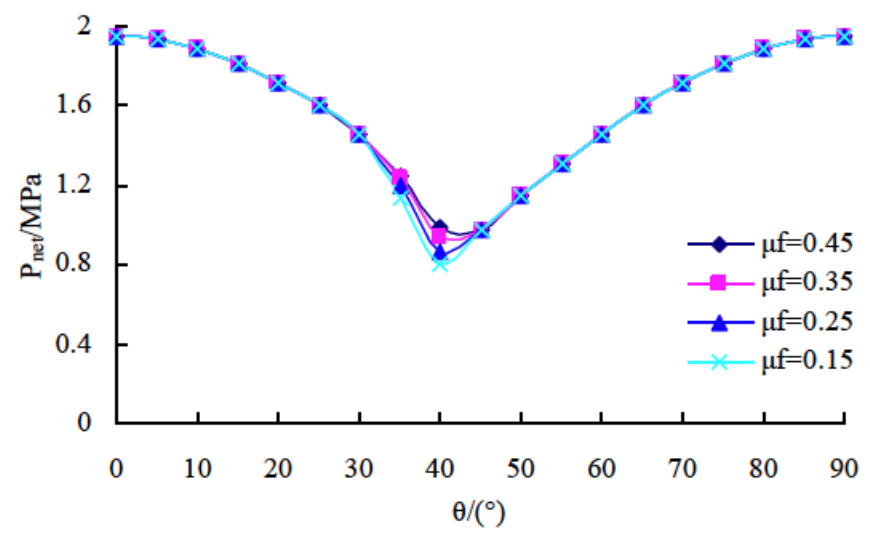

Fig. (8). The curve of minimum net pressure for forming map cracking changing with the variation of angle $\theta$ under different internal friction coefficient of the cleat face.

\section{CONCLUSION}

1) The mechanical mechanism is analyzed for forming map cracking of the coal bed with cleats, the minimum forming net pressure calculation model is established for map cracking, and the field application results showed that the model had good applicability.

2) The net pressure value that was needed for forming map cracking first decreased and then increased with the increasing of the angle between the face cleat and the direction of horizontal minimum principal stress, and the cleats and fissures developed along the horizontal maximum stress were mostly easy to initiate and propagate under the action of water pressure. When the influence of friction was ignored, the maximum net pressure required to form map cracking was equivalent to the difference of horizontal maximum and minimum principle stress.

3) When the angle between the alignments of the face cleat and the butt cleat and the direction of horizontal minimum principal stress was determined, the change of internal friction coefficient of cleat wall had little influence on the required internal critical net pressure. So, before fracturing construction, the cleats and fissures development conditions should be clearly grasped, and this could provide guidance for map cracking hydraulic fracturing.

\section{CONFLICT OF INTEREST}

The authors confirm that this article content has no conflict of interest.

\section{ACKNOWLEDGEMENTS}

The support of the Nature Science Foundation for Youth of Northeast Petroleum University (NEPUBS2014-07) is gratefully acknowledged.

\section{REFERENCES}

[1] C. H. Zhao, S. Yang, and H. Yaoqing, "Study on the effective technology way for mining methane in low permeability coal seam," Journal of China Coal Society, vol. 26, pp. 455-458, 2001.

[2] J. Yong, G. Dali, and Z. Jinzhou, "Factors affecting the production of coalbed methane well after fracturing: a case study of Hangcheng block,"Coal Geology \& Exploitation, vol. 40, pp. 10-13, 2012.

[3] T. Shuhuan, Z. Baocun, and Y. Zhifeng, "Effect of crustal stress on hydraulic fracturing in coalbed methane wells", Journal of China Coal Society, vol. 56, pp. 65-69, 2011.

[4] Z. Shicheng, M. Shanbo, and Z. Jin, "Experimental evaluation of long-term Conductivity of fracturing in coal beds", Acta Geologica Sinica, vol. 82, pp. 1444-1449, 2008.

[5] C., Yuanfang, X. Taishuang, and W. Bailie, "Experimental study on the hydraulic fractures' morphology of coal bed", Natural Gas Geoscience, vol. 24, pp. 134-137, 2013.

[6] L. Qun, X. Yuan, and J. Yanxue, "Fracture network fracturing technique for improving post-fracturing performance of low and ultra-low permeability reservoirs", Acta Geologica Sinica, vol. 30, pp. 237-241, 2009.

[7] W. Dingwei, L. Qun, and X. Yun, "Network fracturing techniques and its application in the field", Acta Geologica Sinica, vol. 32, pp. 280-284, 2011.

[8] Z. Haifeng, C. Mian, and J. Yan, "Rock fracture kinetics of the fracture mesh system in shale gas reservoirs", Petroleum Exploration and Development, vol. 39, pp. 465-470, 2012.

[9] A. Sharma, H. Y. Chen, and L. W. Teufel, "Flow-induced stress distribution in a multi-rate and multi-well reservoir". SPE 39914, 1998.

[10] S. E. Laubach, R .A. Marrett, and J. E. Olson, "Characteristics and origins of coal cleat: a review", International Journal of Coal Geology, vol. 35, pp. 175-207, 1998. 